\title{
A PANEL OF MONOCLONAL ANTIBODIES TO THE RAT OLFACTORY EPITHELIUM ${ }^{1}$
}

\author{
JAMES L. HEMPSTEAD AND JAMES I. MORGAN² \\ Department of Physiological Chemistry and Pharmacology, Roche Institute of Molecular Biology, Roche Research Center, \\ Nutley, New Jersey 07110
}

Received May 18, 1984; Revised July 30, 1984; Accepted August 1, 1984

\begin{abstract}
BALB/c mice were immunized with dissected olfactory mucosa from young adult Sprague-Dawley-derived, $\mathrm{CD}$, rats and antibody-secreting hybridomas were produced. Supernatants from hybridoma cultures were screened by immunocytochemical methods for their ability to react with specific cell populations in frozen sections of rat olfactory epithelium. Approximately 60 clones were identified that showed various degrees of specific staining. These have been classified on the basis of their particular staining specificities. One group of monoclonal antibodies, designated LUM, reacts with the luminal surface of the epithelium. Closer examination reveals these antibodies to react variously with the apical brush border of sustentacular cells, respiratory cilia, and the luminal membrane of respiratory cells. Another group of monoclonal antibodies reacts primarily with sustentacular cells, as is indicated by the SUS prefix. Some antibodies in this group also react with the membranes of respiratory cells and the cells comprising the acini of Bowman's glands. A larger group of antibodies reacts with olfactory neurons and/or their axons, as denoted by the NEU prefix. This group can be further subdivided by the criteria of whether both the olfactory nerve and vomeronasal nerve react with the same monoclonal antibody. A fourth group of monoclonal antibodies, designated GLA, reacts with Bowman's glands and in some instances with secretory cells present in the respiratory mucosa. Two clones, BCL, stain at the level of the basal cell layer just above the lamina propria. A number of other antibodies react with cells and structures of the epithelium that have not been previously described. One of this group, NIS-1, stains globular structures present in the mucosa of the neuroepithelium.
\end{abstract}

It has been pointed out that the olfactory neuroepithelium might represent a unique model system with which to investigate the maturation and regeneration of mammalian neurons (Graziadei, 1971; Graziadei and Monti Graziadei, 1978). The reason for this contention is that the neuroepithelium contains a population of precursor neuroblasts that constantly undergo division and differentiation to replace mature olfactory receptor neurons that are lost at a finite rate throughout the adult life of the animal (Graziadei and Metcalf, 1971; Moulton, 1974; Harding et al., 1977; Graziadei and Monti Graziadei, 1978). Another unique property of this tissue is that, following surgical or chemical lesioning, there ensues the abrupt death of essentially all mature neurons followed by the regeneration of the entire receptor population by the parasynchronous differentiation of the precursor cells present in the basal cell layer (Nagahara, 1940; Andres, 1966; Graziadei, 1973; Harding et al., 1977; Graziadei and Monti Graziadei, 1978; Simmons and Getchell, 1981). Based upon these observations there have been a number of studies suggesting a role for the olfactory bulb, the neural target for olfactory receptor neurons, in the regulation of differentiation of neuroblasts (Harding et al., 1977; Chuah

\footnotetext{
${ }^{1}$ We wish to thank Dr. Frank Margolis for the olfactory marker protein antiserum utilized in this study and for his advice concerning a number of aspects of this work. We also thank Drs. F. Macrides, T. Getchell, and P. Graziadei for their helpful discussion of these data.

${ }^{2}$ To whom correspondence should be addressed.
}

and Farbman, 1983). To extend these investigations to the molecular level it would next be crucial to establish clonal cell lines of olfactory neuroblasts. Our own attempts at generating such cultures have been frustrated by an inability to determine unequivocally the phenotype of cells in vitro. This is because neither neuroblasts in vivo nor cells in dissociated cultures appear to express the one known marker for olfactory neurons, the olfactory marker protein (OMP) (Margolis, 1980). One study has reported the isolation of a clonal neuroblast line (Goldstein and Quinn, 1981); however, these cells did not synthesize OMP. These workers used the initial presence of the dipeptide carnosine and its synthetic enzyme carnosine synthetase as proof of phenotype (Goldstein and Quinn, 1981), since they are enriched in the olfactory neuroepithelium (Margolis, 1974; Harding and Margolis, 1976). However, both carnosine and carnosine synthetase have ubiquitous distributions in mammals (Bauer et al., 1979, 1982; Grillo and Margolis, 1983; and F. L. Margolis, M. Grillo, J. Hempstead, and J. I. Morgan, manuscript in preparation). Thus, the qualitative presence of carnosine or its biosynthetic enzymes cannot be taken as unambiguous proof of cellular identity.

These ambiguities could be at least partially resolved by the production of cell-specific probes. These could take the form of lectins (Hempstead and Morgan, 1983a) or monoclonal antibodies (Hempstead and Morgan, 1983b). This study addresses the latter possibility and reports the production and properties of monoclonal antibodies to the rat olfactory epithelium. 
TABLE I

Classification of the monoclonal antibody library

\begin{tabular}{l} 
Clone \\
\hline $112-\mathrm{A}^{c}$ \\
$1201-\mathrm{A}$ \\
$1306-\mathrm{D}$ \\
$1309-\mathrm{A} 6$
\end{tabular}

$1311-\mathrm{B} 2$

1306-B2

1302-A3

1311-A1

1302-B6

$111-\mathrm{A} 3^{c, d}$

$102-\mathrm{A}^{c}$

1302-C3

1205-A1

1205-C5

1210-A1

1301-D3

1304-A2

1304-A5

1308-C6

1308-D1

1309-A3

1310-D4

1311-C2

1210-A2

1305-B2

1309-C2

1301-D4

1310-A4

2302-C4

1305-C2

1306-B4

1307-A3

1308-D6

1307-D2

1310-C3

1311-D3

1307-A4

Designation Immunocytochemical

LUM-1 Brush border of sustentacular cells
and respiratory cilia

LUM-2 Brush borders of sustentacular cells and apical domains of res piratory cells

LUM-3 LUM-1 Like

LUM-4 LUM-1 like

LUM-5 Brush border of sustentacular cells, apical domain and cilia of respiratory cells

LUM-6 LUM-2 like

LUM-7 LUM-1 like

RES-1 Respiratory cells; sustentacular cells weakly

RES-2 Respiratory cells and their cilia

SUS-1 Sustentacular cells and Bowman's glands

SUS-2 Sustentacular cells, Bowman's glands and respiratory cells

SUS-3 SUS-2 like, glands only weakly reactive

NEU-1 Punctate staining of all nerve bundles

NEU-2 Perineuronal sheath cells

NEU-3 All nerve bundles stained

NEU-4 Neurons and OMP-positive nerve bundles

NEU-5 Weaking staining of neurons but all nerve bundles stained intensely

NEU-6 Perineuronal cells, weak nerve bundle staining

NEU-7 Weak staining of neurons, reacts more strongly with OMP-poor nerve bundles than with positive

NEU-8 Perineuronal sheath cells

NEU-9 Neuronal cell bodies and OMPpositive nerves

NEU-10 All nerve bundles stained, background staining

NEU-11 All nerve bundles stained, background staining

NEU-12 Perineuronal sheath cells and all nerve bundles

NEU-13 Neurons and OMP-positive nerve bundles

NEU-14 Neurons and OMP-positive nerve bundles

BCL-1 Basal cell layer above lamina propria

BCL-2 Indistinguishable from BCL-1

GLA-1 Bowman's glands

GLA-2 Bowman's glands and cells in respiratory tissue

GLA-3 GLA-1 like

GLA-4 GLA-1 like

GLA-5 GLA-1 like

GLA-6 GLA-1 like

GLA-7 GLA-1 like

GLA-8 GLA-1 like

GLA-9 GLA-1 like
TABLE I-continued

\begin{tabular}{|c|c|c|}
\hline Clone No. ${ }^{a}$ & Designation & $\begin{array}{l}\text { Immunocytochemical } \\
\text { Characteristics }^{b}\end{array}$ \\
\hline 1307-A2 & NIS-1 & $\begin{array}{l}\text { Globular structures in neuroepi- } \\
\text { thelium }\end{array}$ \\
\hline $1307-\mathrm{C} 3$ & NIS-2 & NIS-1 like \\
\hline 1308-B1 & NIS-3 & NIS-1 like \\
\hline $107-\mathrm{Al}^{c}$ & PAN-1 & $\begin{array}{l}\text { Global staining of membrane anti- } \\
\text { gen }\end{array}$ \\
\hline 1201-B4 & PAN-2 & PAN-1 like \\
\hline 2308-A5 & PAN-3 & PAN-1 like \\
\hline
\end{tabular}

a The original clonal isolate is indicated, followed by its classificational designation.

${ }^{b}$ The properties of each monoclonal antibody clone as revealed by immunocytochemistry are described in abbreviated form.

${ }^{c}$ Intact cells were used as immunogen rather than a homogenate.

${ }^{d}$ The properties of the SUS-1 clone have been reported previously (Hempstead and Morgan, 1983b).

\section{Materials and Methods}

Adult Sprague-Dawley-derived CD rats (Charles River Breeding Laboratories) were killed by decapitation, and their olfactory epithelia were removed and stored in a liquid nitrogen freezer. For immunization, the epithelia were homogenized in physiological saline using a Polytron (Brinkman Instruments) at maximum setting for $20 \mathrm{sec}$. Female $\mathrm{BALB} / \mathrm{c}$ mice (Charles River) received a primary injection of 10 to 20 mg of epithelium homogenate in Freund's complete adjuvant via the intraperitoneal route. The mice received a booster injection 6 weeks later in Freund's incomplete adjuvant as for the primary immunization. In one series of fusions, as denoted in Table I, mice were immunized twice with intact cells from rat epithelium as described previously (Hempstead and Morgan, 1983b). Antibody-secreting hybridomas were then generated by fusing dissociated spleen cells and PAI-O myeloma (provided by Dr. T. Staehlin of Hoffmann-La Roche) by standard techniques (Kohler and Milstein, 1975; Fazekas de St. Groth and Scheidegger, 1980), which have been described in some detail for this system elsewhere (Morgan, 1984).

Frozen sections of young adult rat olfactory epithelium were produced as described previously (Hempstead and Morgan, 1983b). Hybridoma supernatants were screened for specific immunoreactivity by double indirect immunofluorescence against anti-OMP antibodies as also detailed before (Hempstead and Morgan, 1983b). Where higher magnifications were required to assess precise localization of immunoreactivity, frozen sections were examined by use of the avidin-biotin immunoperoxidase procedure, using the protocol provided by the supplier (Vector Laboratories, Inc.). Specific antibody-secreting clones were recloned and ascites tumors were generated according to standard procedures (Kohler and Milstein, 1975). Anti-OMP antiserum was provided by Dr. F. Margolis of the Roche Institute. All reagents used for immunofluorescence have been described previously (Hempstead and Morgan, 1983b). The sources of all reagents for monoclonal antibody production have also been exhaustively listed elsewhere (Morgan, 1984).

\section{Results}

Three hybridoma fusions yielded approximately 800 clones of which about 60 exhibited some degree of cell-specific staining of the rat olfactory epithelium. The majority of the clones secreted antibodies that reacted with identifiable cells or structures within the neuroepithelium and have been classified by the predominant cell type stained. These clones are categorized in Table I, a three-letter prefix being used to denote the primary immunoreactive cell type. Another group of clones secreted antibodies that reacted with elements of the neuroepithelium that could not be identified by us from the currently available literature relating to the structure of the rodent olfactory system. Such clones have been denoted by the prefix NIS, and only one subtype of this group is either listed or discussed here (Table I). A third class of antibodies gave a global, or less 
specific, staining of the olfactory epithelium and its surrounding tissues and is included in Table I for completeness. In vitro studies have revealed that this less specific class of monoclonal antibodies, designated PAN, invariably reacts with antigenic determinants present at the outer surface of the plasma membrane (data not presented).

Monoclonal antibodies reactive with the luminal boundary $(L U M)$. Seven clones have been derived that react with the luminal surface of the olfactory and respiratory epithelia (Table I, Figs. 1 and 2). All members of the LUM class of antibodies stain the outermost boundary of sustentacular cells (Fig. 2). In addition, most stain cilia in the adjacent respiratory epithelium (Fig. 2), although they do not show reactivity with other elements of these tissues (Table I, Fig. 2). Members of the LUM group may also exhibit staining of the apical regions of respiratory cells (Table I, Fig. 2). We have not yet detected clones that unambiguously stain receptor cilia; the reasons for this may be technical or may reflect low antigenicity of these structures.

From this it may be seen that the LUM antibodies may be subdivided into two groups, those that react primarily with sustentacular cell brush borders and respiratory cilia (LUM-1like) and those that react with the sustentacular cell brush border and the apical respiratory membrane (LUM-2-like). The LUM-3 monoclonal antibody has proven to be particularly valuable since it can be used to demarcate respiratory and olfactory epithelia in indirect double immunofluorescence experiments (Fig. 1). This is because, although LUM-3 only stains a narrow band of membrane on the sustentacular cells overlying the olfactory neuroepithelium, it reacts to a deeper level on respiratory cell membranes. Furthermore, studies on cultured respiratory epithelium reveal that the LUM-3 antigen is expressed on the external surface of the plasma membrane, accessible to antibody in unfixed cells (J. L. Hempstead and J. I. Morgan, unpublished observation).

Sustentacular cell-specific monoclonal antibodies (SUS). Three clones have been isolated that secrete antibodies reactive with sustentacular cells, one of which, SUS-1, has been reported upon previously (Hempstead and Morgan, 1983b) and is included here for completeness (Table I). SUS-1, like SUS-2 and SUS-3, reacts intensely with the upper portion of the cell body of sustentacular cells (Hempstead and Morgan, 1983b; Fig. 3).
The basal processes of sustentacular cells are less intensely reactive (Fig. 3 ).

SUS-1 and SUS-2 also react with the cells comprising at least some of the Bowman's glands although they do not apparently react with the contents of the acinus (Hempstead and Morgan, 1983b). This latter point is in contrast to the staining observed with another group of monoclonal antibodies, described below, that react with both cells and gland contents. SUS-2 and SUS-3 antibodies also react with respiratory cells but, unlike most of the LUM antibodies, they do not react with respiratory cilia (Fig. 3 ).

Two other clones will be mentioned under this heading since they were initially classified as SUS-type antibodies. However, these clonal antibodies react much more intensely with respiratory epithelium than with sustentacular cells. For this reason these two clones have been designated RES-1 and RES-2 to reflect this fact (Table I). It is hoped that these clones may prove useful in eliminating respiratory cells from cultures of olfactory epithelum.

Antibodies reacting with neurons and nerve bundles (NEU). The largest group of hybridomas isolated secreted antibodies reactive with neurons and nerve bundles (Table I, Figs. 4 and 5). Although several of the clones gave staining similar to that of the OMP (Fig. 4), none of them could be shown to be immunocross-reactive with this protein in dot blot or radio precipitation assays (data not presented). Indeed, in preliminary attempts to raise serum antibody titers to rat OMP in mouse, we were unable to demonstrate specific antibody production, possibly indicating low immunogenicity of rat OMP in the mouse.

OMP staining of the olfactory epithelium reveals a number of nerve bundles that are only weakly reactive with the antiserum, whereas the majority are highly reactive (Fig. $4 A$ ). The position of these nerve trunks, running along the central septum, as well as their size, would lead us to conclude that they are elements of the vomeronasal nerve. It is interesting to note that, whereas some antibodies are, like OMP, only weakly reactive or unreactive with these nerve tracts, others such as NEU-5 stain both OMP-positive and these OMP-negative nerve bundles (Fig. 5). Based upon this criterion, the NEU antibodies may be subdivided into those that stain like OMP (NEU-4, 9, 13, and 14), those that stain all nerve bundles
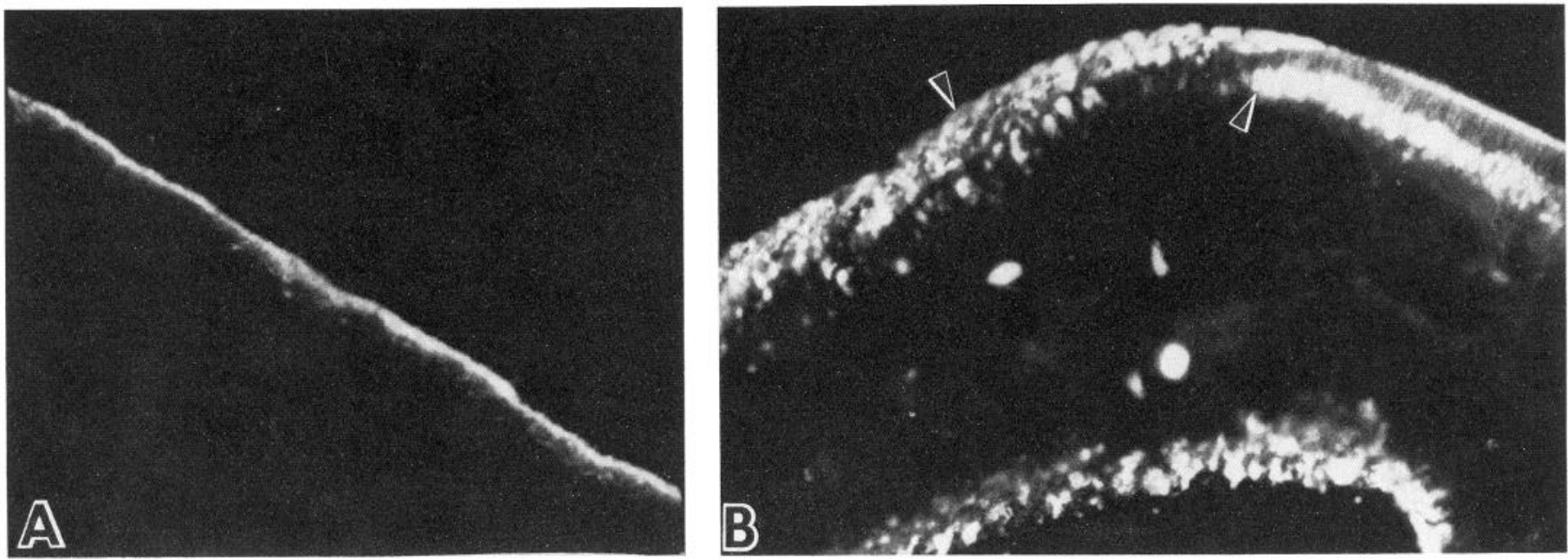

Figure 1. Staining characteristics of luminal-reactive (LUM) antibodies. A, Staining of olfactory epithelium by the LUM-1 monoclonal antibody using indirect single immunofluorescence. $B$, Reaction of LUM-3 antibody with both olfactory and respiratory epithelia using indirect double immunofluorescence against an anti-OMP antiserum. The left arrowhead shows the staining of olfactory receptor neurons by the OMP antiserum at the junction between olfactory and respiratory tissue. The right arrowhead indicates the staining of respiratory epithelium by the LUM-3 antibody. Magnification $\times 125$. 

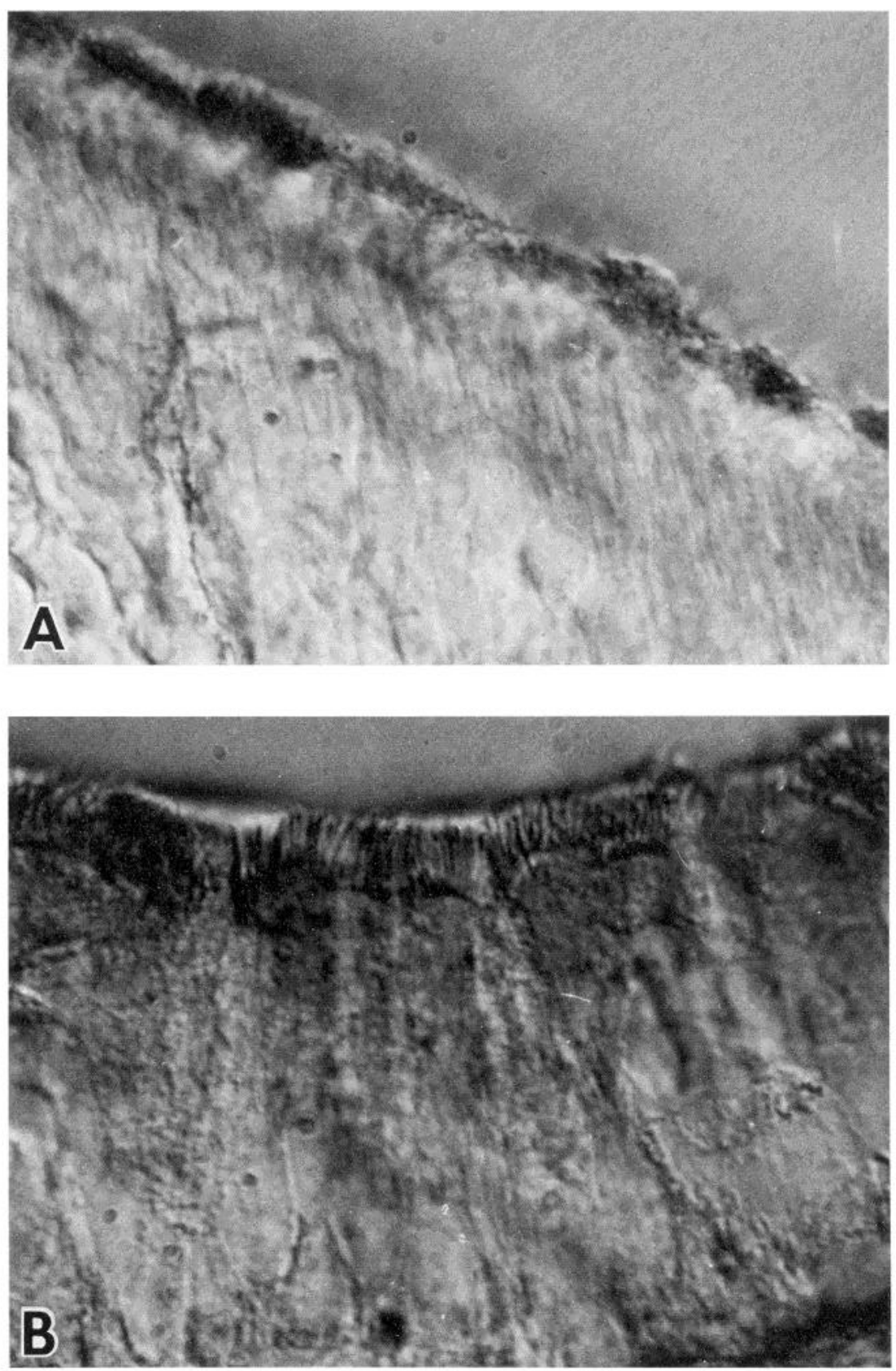

Figure 2. Staining characteristics of luminal-reactive (LUM) antibodies studied at higher magnifications. A, Reaction of LUM-1 monoclonal antibody with the apical surface of the olfactory neuroepithelium using the avidin-biotin immunoperoxidase procedure. $B$, Staining of the same antibody on the cilia and upper domains of the cells comprising respiratory epithelium. Magnification $\times 1250$.
(NEU-1, 3, 5, 11, and 12), and those that stain OMP-negative tracts (the putative vomeronasal nerve) more intensely than OMP-positive nerve bundles (NEU-7 and 10).

Two clones, NEU-2 and NEU-6, stain the sheath encompassing the nerve bundles and give weak staining of the bundles themselves (Table I). Cultures of rat olfactory epithelium contain proliferating glial fibrillar acid protein-positive cells which we have supposed to be perineuronal sheath cells (Hempstead and Morgan, 1983c). The above antibodies may shed more light upon this contention.

Antibodies reactive with the basal cell layer $(B C L)$. Two clones have been isolated that give a relatively specific reaction with the region of the basal cell layer immediately above the basal lamina (Table I, Fig. 6). Although a number of the NEU antibodies stained the olfactory mucosa down to the basement membrane, these were the only clones found to give this specific staining pattern. In additional studies we have shown that both of the BCL antibodies also react with perikarya of short axon cells in the olfactory bulb (J. L. Hempstead and J. I. Morgan, manuscript in preparation), indicating some degree of specificity for cells of a neuronal character. However, it remains to be established whether the BCL antibodies actually react with basal cells, the putative precursors of olfactory receptor neurons (Graziadei, 1971).

Antibodies reactive with Bowman's glands (GLA). Nine clones stained the cells and acinar contents of Bowman's glands (Table I, Figs. 7 and 8). The designation of Bowman's gland localization was based upon the known topographical distribution of these structures in rodents (Bang and Bang, 1959; Graziadei, 1971). The antibodies also clearly reveal duct-like structures linking the acinus of the gland to the surface of the neuroepithelium (Fig. 7). These staining characteristics are indistinguishable from those described previously using histochemical (Cuschieri and Bannister, 1974), immunocytochemi- 

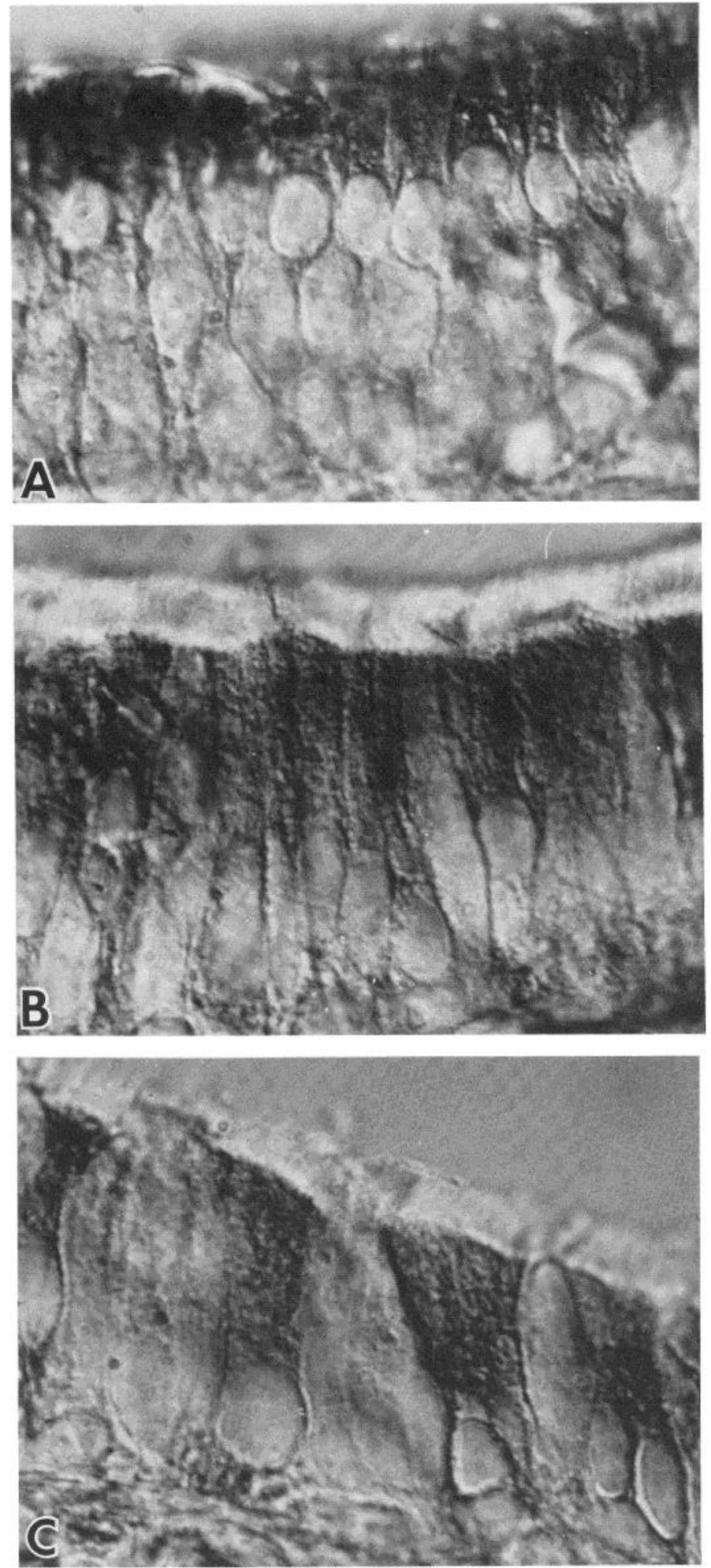

Figure 3. Staining characteristics of sustentacular cell-reactive (SUS) antibodies studied at higher magnifications. A, Staining of sustentacular cells at high magnification using the avidin-biotin immunoperoxidase procedure and the SUS- 2 antibody. The typical wine glass-shaped cell body is evident with the most intense staining being concentrated over the upper portion of the cell. Basal processes may also be visualized. $B$ and $C$, Reaction of monoclonal antibodies SUS-2 and SUS-3, respectively, with respiratory epithelium. Note that, whereas the cells are intensely stained, there is no evidence of reactivity with cilia as observed with LUM-1 in Figure 2. Magnification $\times 1250$. cal (Hempstead and Morgan, 1983a; Margolis et al., 1983), and fluorescent lectin binding (Hempstead and Morgan, 1983a) techniques for Bowman's glands.

Whereas no other cell or structure within olfactory neuroepithelium was found to react with the GLA antibodies, a subset of cells in the respiratory epithelium was stained (Fig. 8). These cells do not appear to be ciliated and are presumed to be secretory cells.

Miscellaneous antibodies (NIS). A number of clones have been identified that react with, as yet, unknown cell types within the olfactory epithelium (Table I). NIS-1 through NIS4 all appear to react with similar structures present in the mucosa of the neuroepithelium (Figs. 9 and 10). The reactive elements are globular in nature and give the impression of having a basal process (Figs. $9 B$ and $10 B$ ). Although they may be observed throughout the olfactory epithelium, they appear to have patches of high density as shown in Figure $9 A$. The significance of these structures is not understood at the present time.

\section{Discussion}

Based upon immunocytochemical criteria, a collection of monoclonal antibodies has been raised to the major cell types of the rat olfactory epithelium and cells of the juxtaposing respiratory tissue (Table I). Although we can draw no conclusions regarding the number of antigenic determinants represented in the library at this juncture, a number of points are raised concerning functional or possible developmental relationships between various cell types based upon the immunocytochemical data.

Antibodies that react with the cells lining the luminal boundary of the respiratory and olfactory mucosae are qualitatively homologous. Thus, essentially all seven LUM antibodies bind to the apical surface, most probably microvilli, of sustentacular cells and the cilia of respiratory cells (Fig. 2). Since these antibodies do not show a reaction with other cells within the structure, this might suggest that the antigenic determinants are relevant to common functions of the apical domains of sustentacular and respiratory cells. Another series of monoclonal antibodies, SUS-2 and SUS-3, also shares a determinant on sustentacular cells and respiratory epithelial cells (Fig. 3). In this instance, however, reactivity on the sustentacular cell is not restricted to the apical portion of the cell (Fig. 3). Furthermore, reactivity on the respiratory cell does not include the cilia as it does for the LUM class of monoclonal antibodies. This may again reveal a common function of sustentacular cells and respiratory cells.

Some of the sustentacular cell antibodies react with Bowman's glands (Hempstead and Morgan, 1983b). Such an observation could also be a reflection of a common function such as secretion; however, it has been brought to our attention that sustentacular cells and the cells comprising Bowman's glands may have the same embryonic origins in the non-neural ectoderm of the olfactory placode (Klein and Graziadei, 1983). Thus, in this instance the SUS antibodies may be detecting an antigen that reflects the lineage of sustentacular cells and Bowman's gland cells rather than specific functions of the two cell types.

Some potentially interesting parallels of function are also revealed by the neuronal antibodies (NEU). Whereas some antibodies react only with OMP-positive nerve bundles (e.g., NEU-4; Fig. 4), other members of the library also react with nerve tracts that are OMP poor (e.g., NEU-5; Fig. 5). However, it should be pointed out that only NEU- 6 and NEU-12 monoclonal antibodies stain neurons or axons in any other region of the brain examined to date (J. L. Hempstead an J. I. Morgan, unpublished observation). We would be led to conclude, there- 

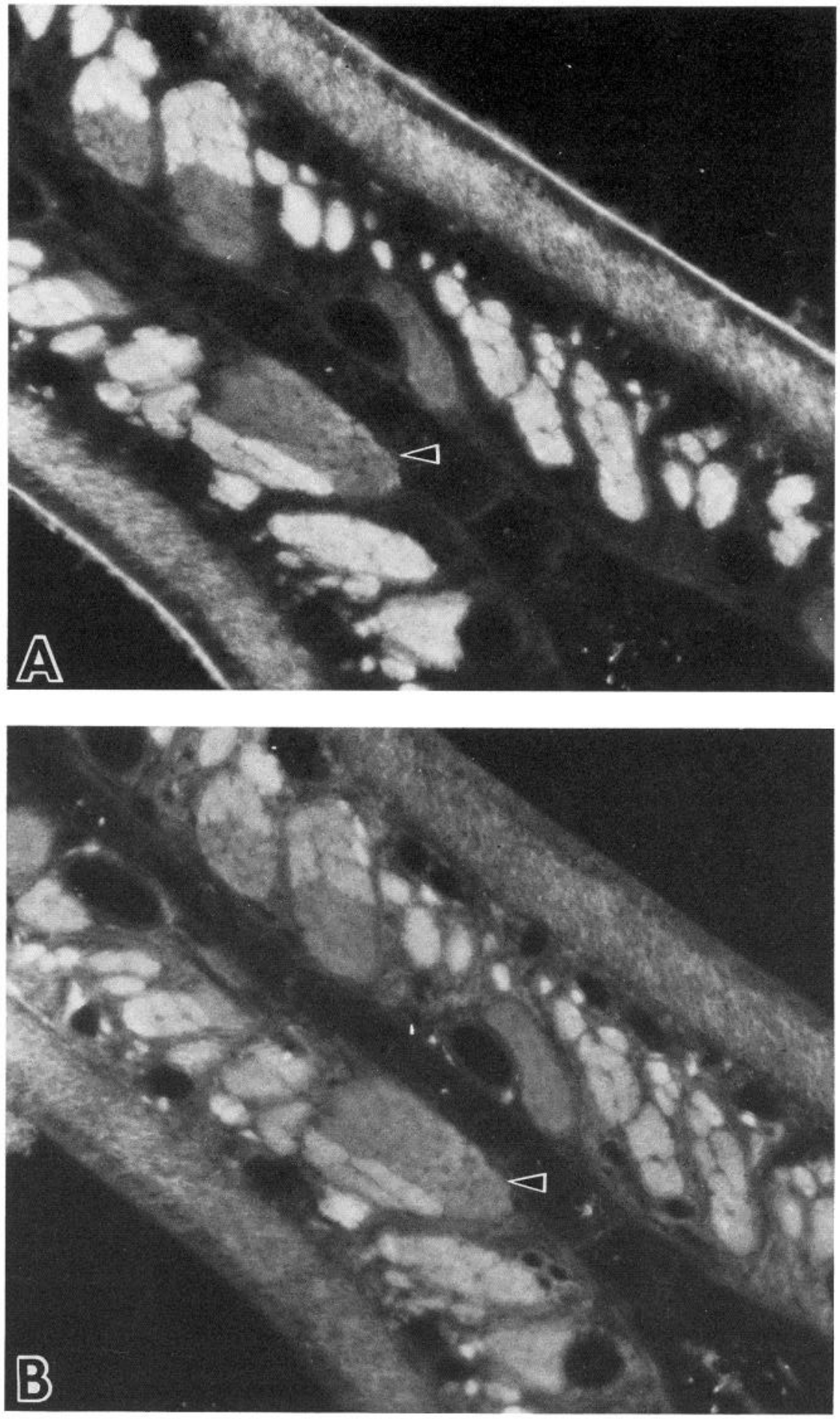

Figure 4. Staining of neurons and nerve bundles by NEU-4 antibody: Using double indirect immunofluorescence, the staining distributions of an OMP antiserum and the NEU-4 monoclonal antibody have been compared. A, Staining distribution of OMP; the arrowhead indicates one of several OMP-poor nerve bundles present in the section. $B$, The same field exposed for the presence of the NEU-4 antibody. It can be seen that the OMP-poor nerve bundles are also NEU-4 poor (see arrowhead). The staining of the neuron layer is also comparable for both antibodies. Magnification $\times 125$. fore, that some functional homology might exist between the OMP-positive neurons and the OMP-poor nerve bundles since they apparently share some common determinants (Fig. 5). We have suggested that, based upon the position and size of the OMP-poor nerve bundles, these should be elements of the vomeronasal nerve (McCotter, 1912; Herrick, 1921; BojsenMoller, 1964; Barber and Raisman, 1974). The fact that the structure apparently contains OMP in lesser amounts than does the olfactory epithelium proper is also consistent with the distribution of the marker protein (Margolis, 1972; Farbman and Margolis, 1980). Since both the olfactory epithelium and the vomeronasal organ are supposed to be involved in olfactory discrimination (Tucker, 1971), the presence of common antigenic determinants might point to specific molecules having roles in the olfactory process.

With the production of this panel of cell-specific antibodies, it may now be possible to characterize cultured cells derived from the olfactory system. In addition, since a number of the antigenic determinants for these antibodies are membrane associated, this may permit selection of specific cell populations. Of a more immediate importance is the role played by the various neuronal antigens demonstrated here in olfaction. It 
Figure 5. Staining of neurons and nerve bundles by NEU-5 antibody. Double indirect immunofluorescence was performed on a serial section to that in Figure 6 using similar techniques. In this instance, $A$ shows the distribution of OMP and the arrowhead again indicates an OMP-poor nerve bundle. $B$ shows the same field for the NEU-5 antibody. In this instance the OMP-poor nerve tract is highly reactive with the NEU-5 reagent. It might also be noted that, although the NEU-5 antibody reacts intensely with nerve bundles, indeed, better than OMP, it reacts poorly with adult receptor neurons, unlike the results obtained with NEU-4. Magnification $\times 125$.
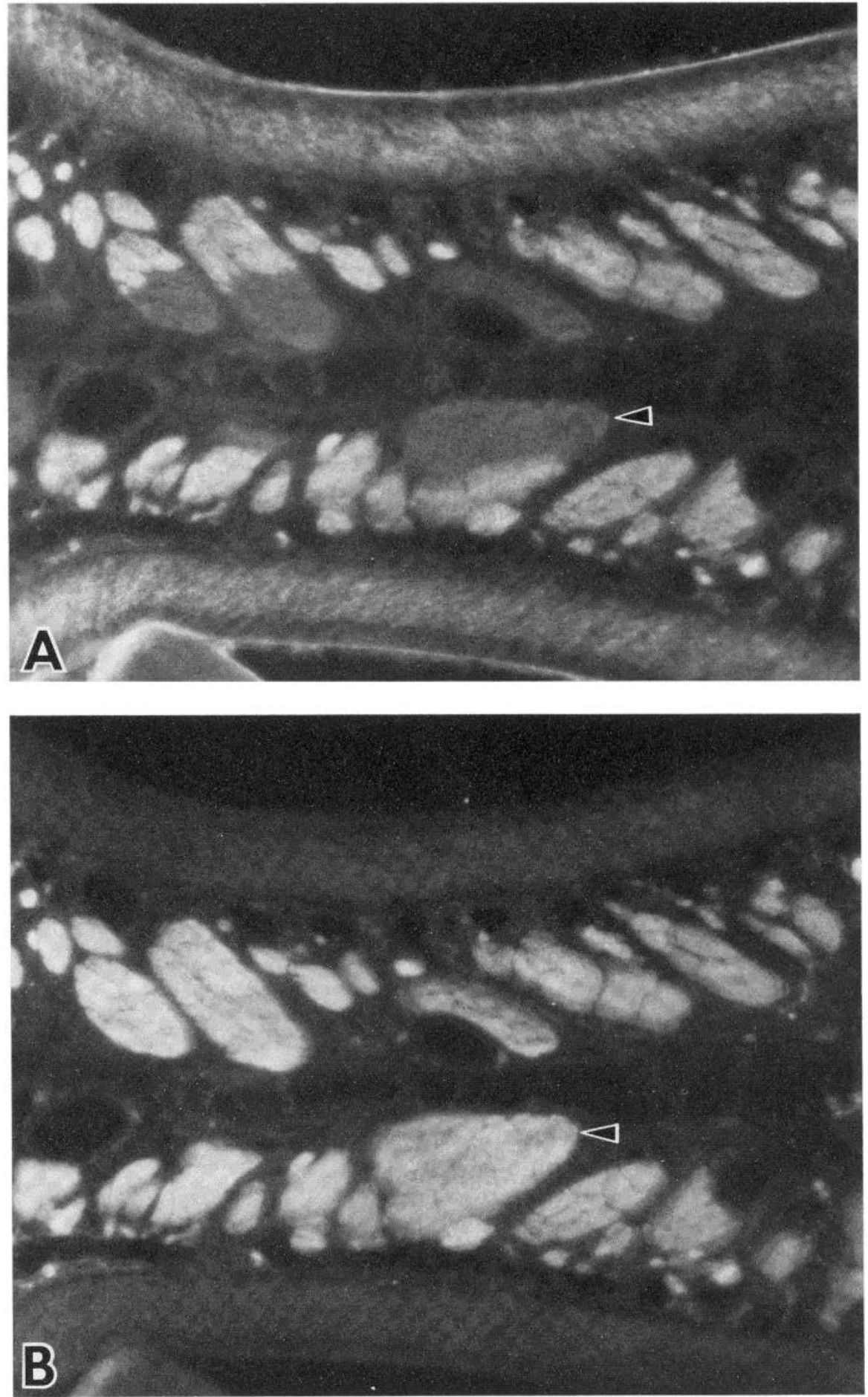


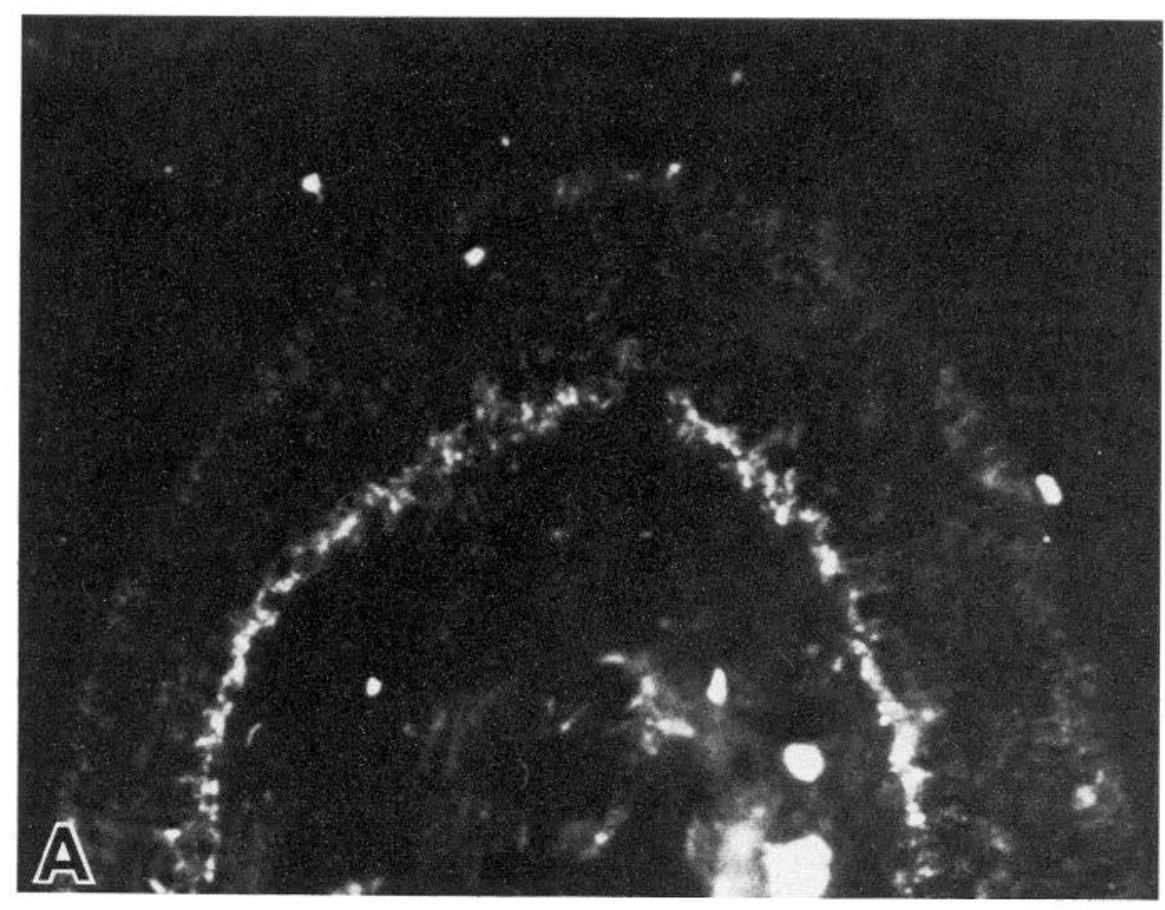

Figure 6. Immunocytochemical properties of antibodies reactive with the basal cell layer. Two monoclonal antibodies, BCL-1 $(A)$ and BCL-2 $(B)$, can be shown to react with the basal cell layer just above the lamina propria by single indirect immunofluorescence. Magnification $\times$ 125.

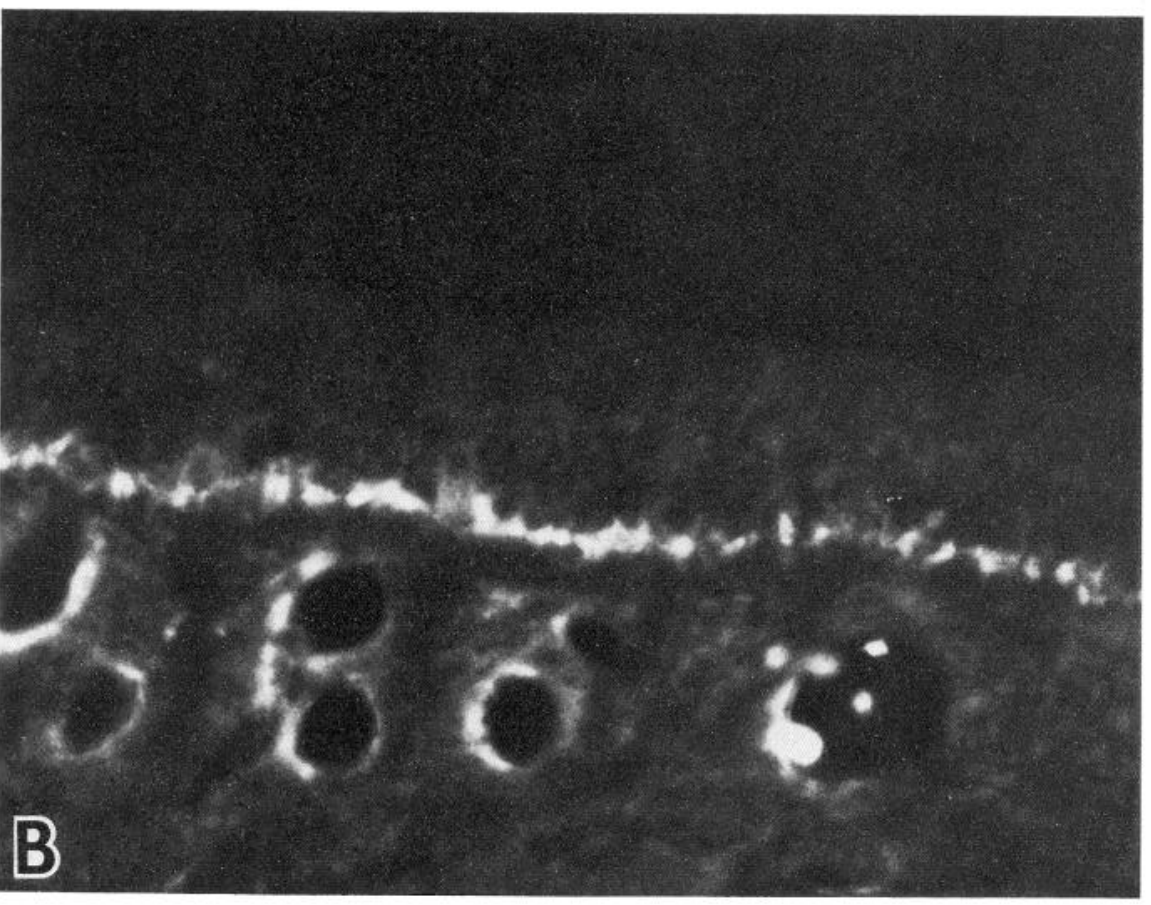




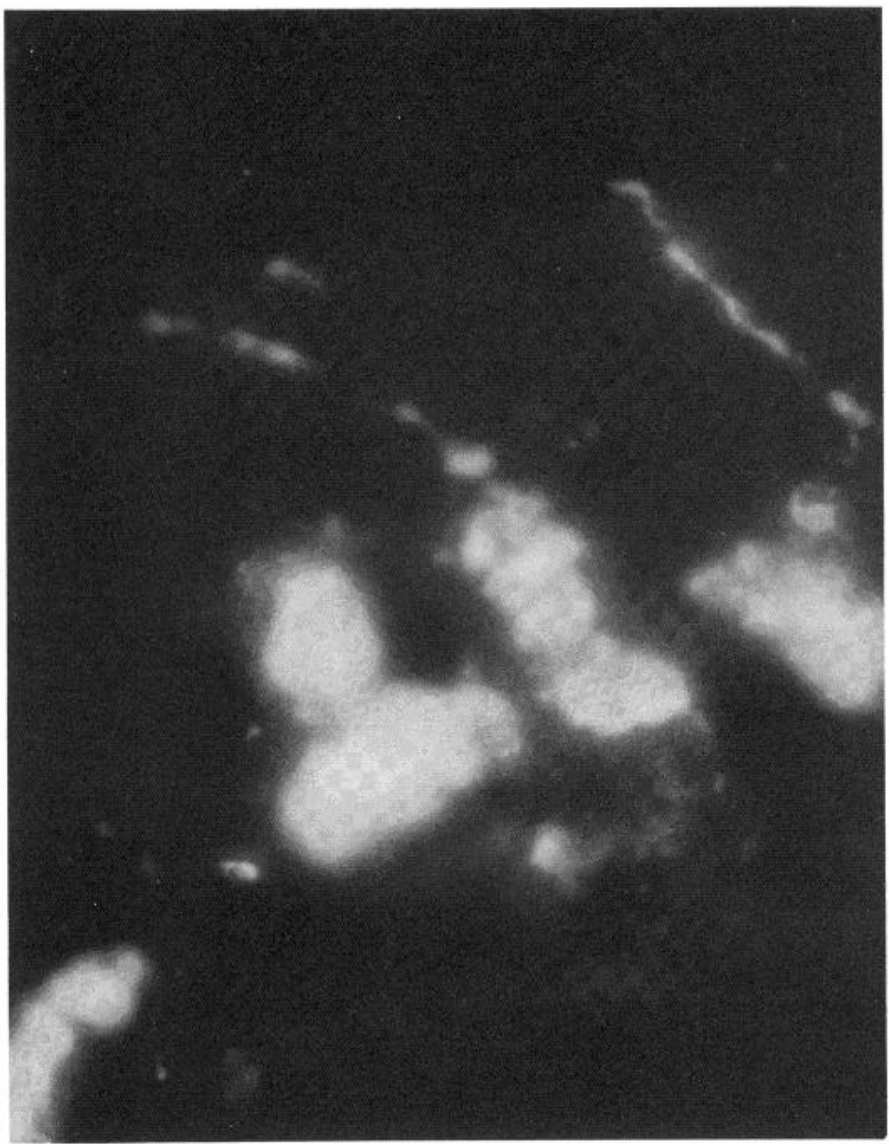

Figure 7. Staining of Bowman's glands by the GLA-2 monoclonal antibody. Using single indirect immunofluorescence, GLA-2 antibody can be shown to stain the acinar contents of Bowman's glands in the lamina propria mucosae. In addition, ducts and/or their contents may be visualized with the same antibody passing through the olfactory mucosa to the lumen of the nasal cavity. Magnification $\times 450$.
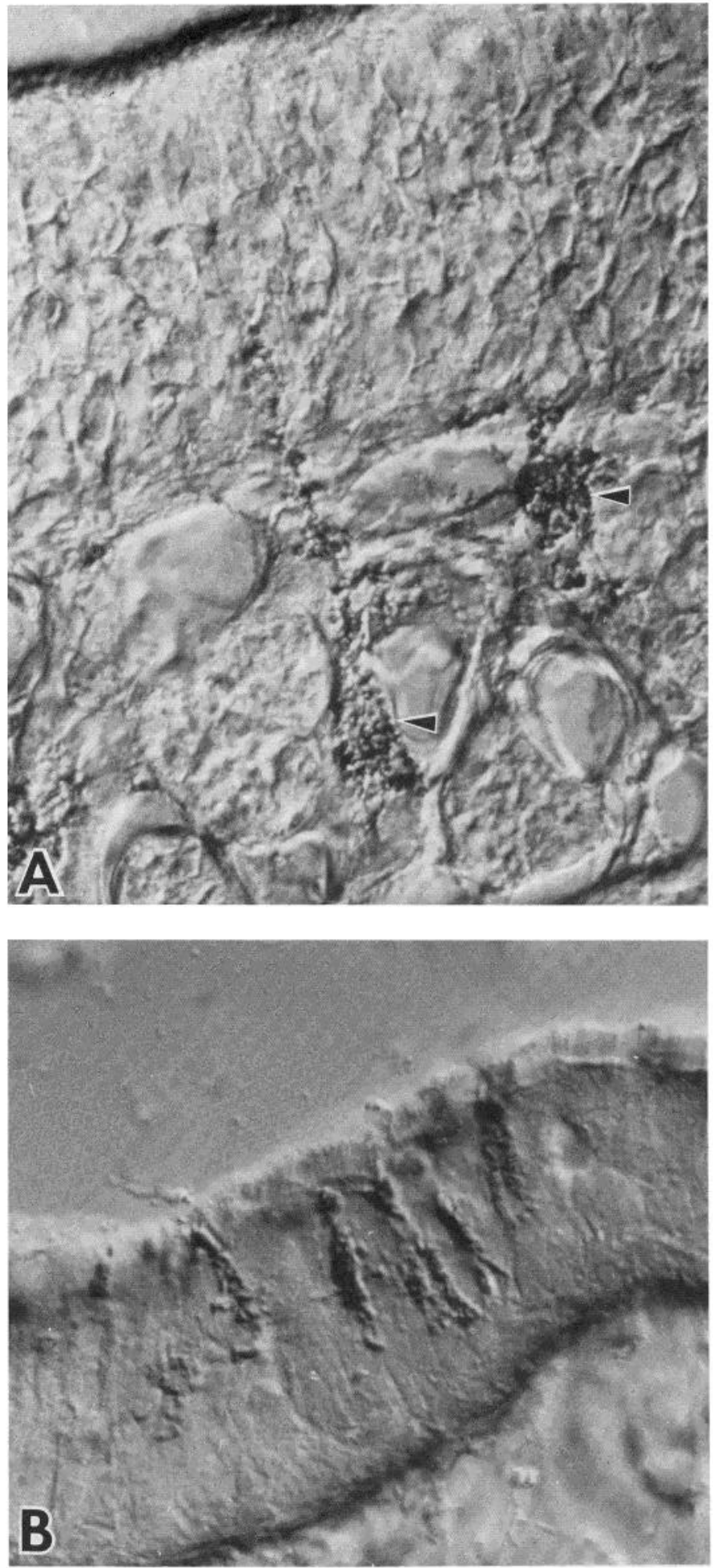

Figure 8. Staining of olfactory and respiratory epithelia with GLA-2 antibody. At higher magnification $(\times 1250)$, staining of gland-like structures in the olfactory epithelium (arrowheads) may be confirmed for the GLA-2 antibody $(A)$. The same antibody also reacts with individual cellular elements in the respiratory epithelium $(B)$ as indicated by the presence of ciliated cells. The reactive elements are all present above the basal lamina which is in contrast to the situation in olfactory tissue. 


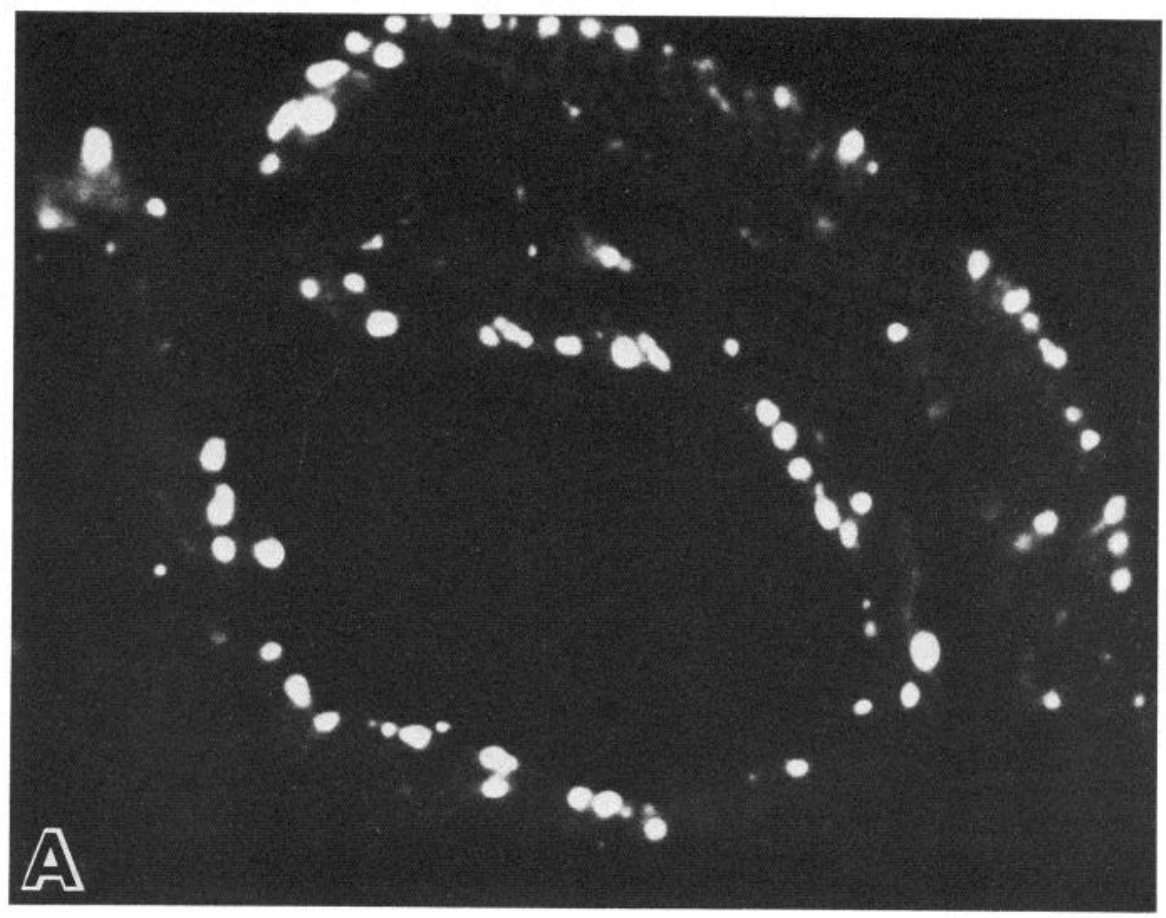

Figure 9. Miscellaneous antibodies reacting with unidentified elements of the olfactory neuroepithelium (NIS). In single indirect immunofluorescence, monoclonal antibody NIS-1 reacts with globular structures in the olfactory neuroepithelium $(A$, magnification $\times 125)$. At higher

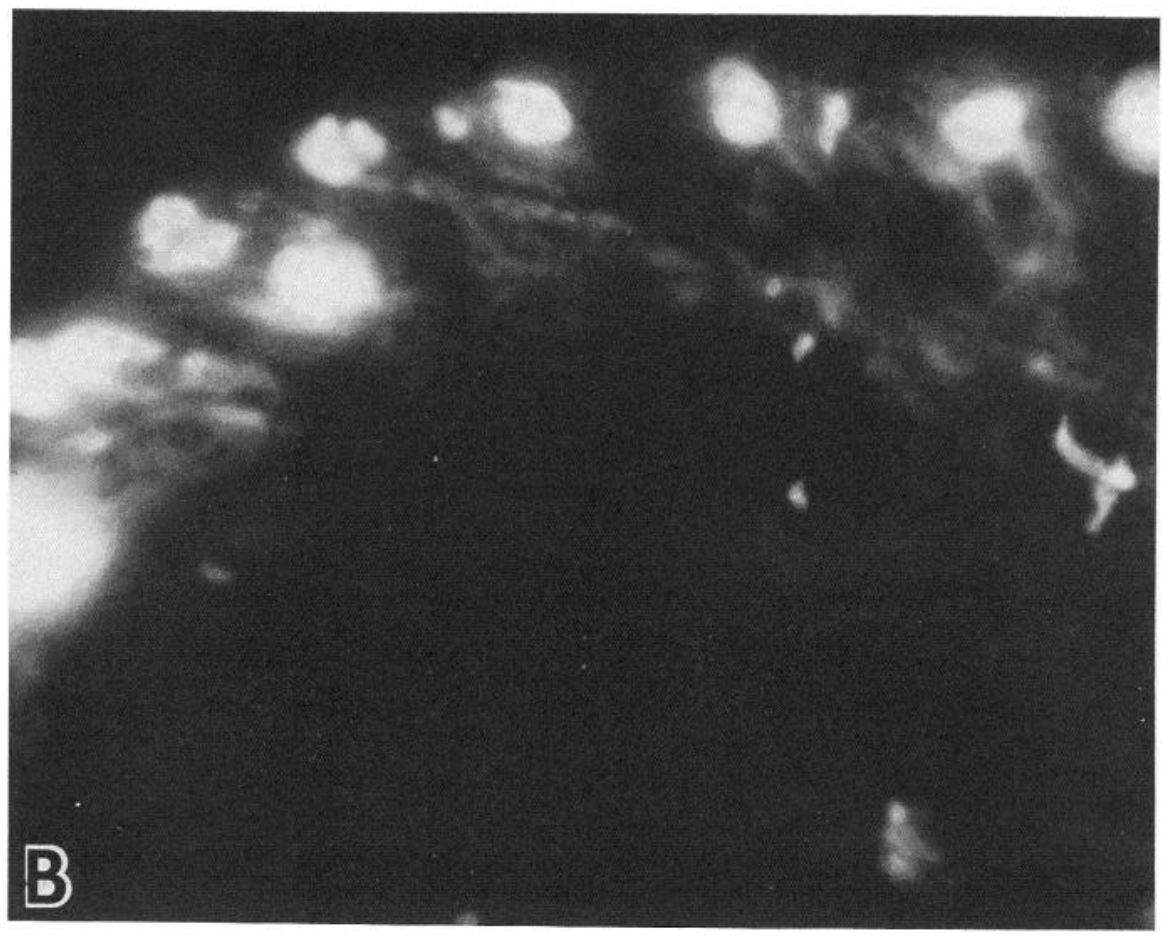
magnifications $(B$, magnification $\times 600)$, these structures give the impression of possessing basal processes. 
Figure 10. A high power study of NIS-1-reactive structures in the olfactory epithelium. $A$, Staining of NIS-1-positive structures using the avidin-biotin immunoperoxidase procedure at $x$ 600 magnification. Here it may be seen that the immunoreactive elements are located at the interface of the receptor neuronsustentacular cell layers. The structures appear to be composed of several globular elements as is more clearly shown in $B$ at $\times 1500$ magnification. As in the immunofluorescence study (Fig. 9), there is often the impression of basal processes associated with the NIS-positive structures.
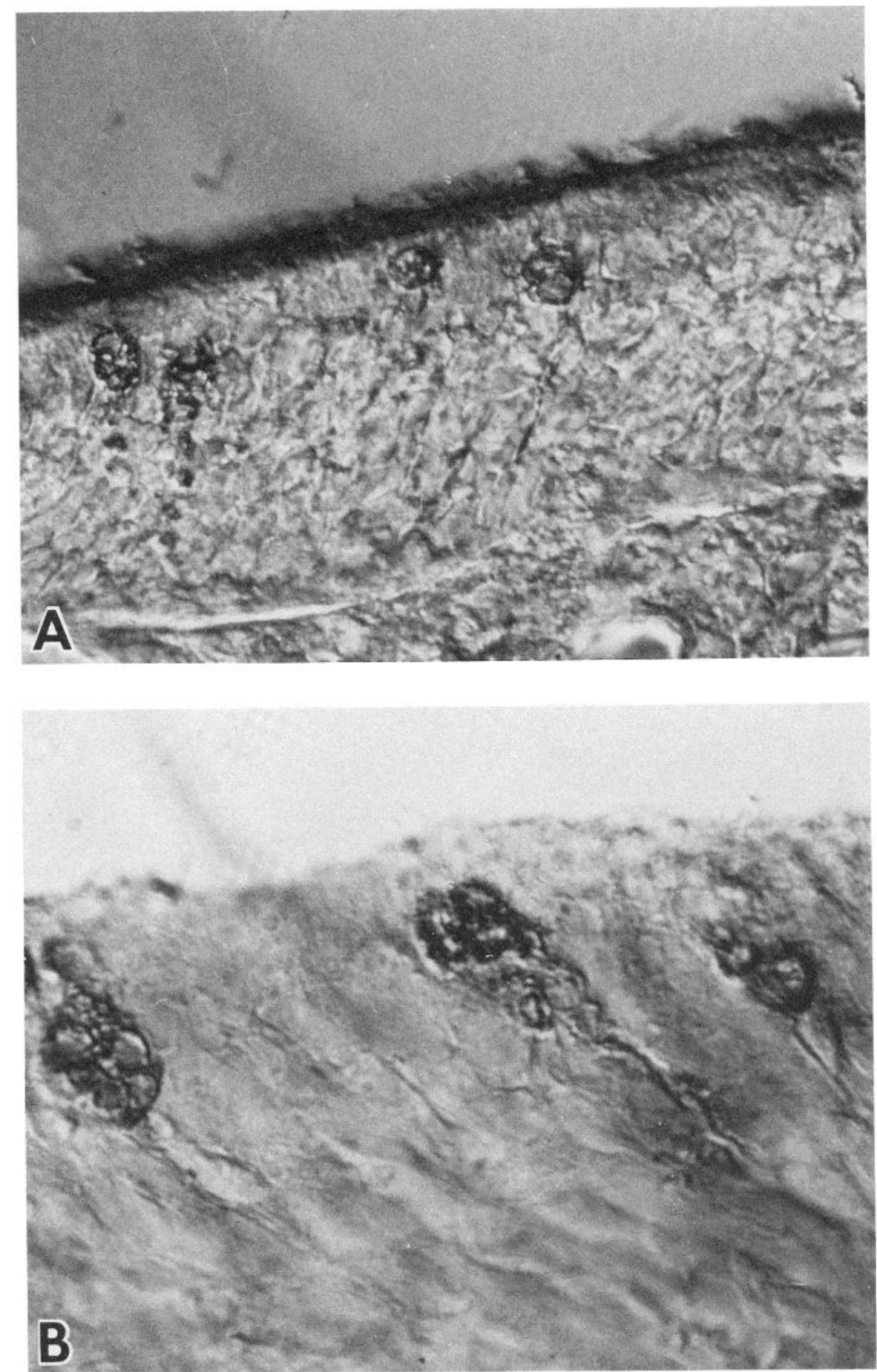
will thus be of some interest to establish not only the chcmical nature of these determinants but also the control of their expression in olfactory tissue.

\section{References}

Andres, K. H. (1966) Der Feinbau der Regio olfactoria von Makrosmatikern. Z. Zellforsch. Mikrosk. Anat. 69: 140-154.

Bang, B. G., and F. B. Bang (1959) A comparative study of the vertebrate nasal chamber in relation to upper respiratory infections. Bull. Johns Hopkins Hosp. 104: 107-149.

Barber, P. C., and G. Raisman (1974) An autoradiographic investigation of the projection of the vomeronasal organ to the accessory olfactory bulb in the mouse. Brain Res. $81: 21-30$.

Bauer, K., J. Salnikow, F. DeVitry, A. Tixier-Vidal, and H. Kleinkauf (1979) Characterization and biosynthesis of omega-aminoacyl amino acids from rat brain and the $\mathrm{C} 6$ glioma cell line. J. Biol. Chem. 254: 6402-6407.

Bauer, K., K. Hallermayer, J. Salnikow, H. Kleinkauf, and B. Hamprecht (1982) Biosynthesis of carnosine and related peptides by glial cells in primary culture. J. Biol. Chem. 257: 3593-3597.

Bojsen-Moller, F. (1964) Topography of the nasal glands in rats and some other mammals. Anat. Rec. 150: 11-24.

Chuah, M., and A. I. Farbman (1983) Olfactory bulb increases marker protein in olfactory receptor cells. J. Neurosci. 3: 2197-2205.

Cuschieri, A., and L. H. Bannister (1974) Some histochemical observations on the mucosubstances of the nasal glands of the mouse. Histochem. J. 6: 543-558.

Farbman, A. I., and F. L. Margolis (1980) Olfactory marker protein during ontogeny: Immunohistochemical localization. Dev. Biol. 74: 205-215.

Fazekas De St. Groth, S., and D. Scheidegger (1980) Production of monoclonal antibodies: Strategy and tactics. J. Immunol. Methods 35: 1-21.

Goldstein, N. I., and M. R. Quinn (1981) A novel cell line isolated from the murine olfactory mucosa. In Vitro 17: 593-598.

Graziadei, P. P. C. (1971). The olfactory mucosa in vertebrates. In IIandbook of Sensory Physiology. Vol. IV: Chemical Senses, Sect. 1: Olfaction, K. Beidler, ed., pp. 27-58, Springer-Verlag, Berlin.

Graziadei, P. P. C. (1973) Cell dynamics in the olfactory mucosa. Tissue Cell 5: 113-131.

Graziadei, P. P. C., and J. F. Metcalf (1971) Autoradiographic and ultrastructural observations on the frog's olfactory mucosa. Z. Zellforsch. Mikrosk. Anat. 116: 305-318.

Graziadei, P. P. C., and G. A. Monti Graziadei (1978) The olfactory system. A model for the study of neurogenesis and axon regeneration in mammals. In Neuronal Plasticity, C. Cotman, ed., pp. 131-153, Raven Press, New York.

Grillo, M., and F. L. Margolis (1983) Rabbit muscle carnosine synthetase: Purification and generation of mouse antisera. Soc. Neurosci. Abstr. 9: 1134.

Harding, J., and F. L. Margolis (1976) Denervation in the primary olfactory pathway of mice. III. Effect on enzymes of carnosine metaholism. Brain Res. 110: 351-360.

Harding, J., P. P. C. Graziadei, G. A. Monti Graziadei, and F. L. Margolis (1977) Denervation in the primary olfactory pathway of mice. IV. Biochemical and morphological evidence for neuronal replacement following nerve section. Brain Res. 132: 11-28.

Hempstead, J. L., and J. I. Morgan (1983a) Fluorescent lectins as cellspecific markers for the rat olfactory epithelium. Chem. Senses 8 $107-120$.

Hempstead, J. L., and J. I. Morgan (1983b) Monoclonal antibodies to the rat olfactory sustentacular cell. Brain Res. 288; 289-295.

Hempstead, J. L., and J. I. Morgan (1983c) Culture and immunocytochemical characterization of the rat olfactory epithelium. Soc. Neurosci. Abstr. 9: 464

Herrick, C. J. (1921) The connections of the vomeronasal nerve, accessory olfactory bulb and amygdala in amphibia. J. Comp. Neurol. 33: $213-280$

Klein, S. L., and P. P. C. Graziadei (1983) The differentiation of the olfactory placode in Xenopus laevis: A light and electron microscope study. J. Comp. Neurol. 217: 17-30.

Kohler, G., and C. Milstein (1975) Continuous culture of fused cells secreting antibody of defined specificity. Nature 256: 495-497.

Margolis, F. L. (1972) Solid-phase radioimmunoassay using ${ }^{3} \mathrm{H}$-labeled antigen for the mouse olfactory bulb specific protein. Anal. Biochem. 50: 602-607.

Margolis, F. L. (1974) Carnosine in the primary olfactory pathway. Science 181: 909-911.

Margolis, F. L. (1980). A marker protein for the olfactory chemoreceptor neuron. In Proteins of the Nervous System, R. A. Bradshaw and D. M. Schneider, eds., pp. 59-84, Raven Press, New York.

Margolis, F. L., M. Grillo, N. Granot-Reisfeld, and A. I. Farbman(1983) Purification, characterization and immunocytochemical localization of mouse kidney carnosinase. Biochim. Biophys. Acta 744: 237-248.

McCotter, R. E. (1912) The connection of the vomeronasal nerves with the accessory olfactory bulb in the opossum and other mammals. Anat. Rec. 6: 299-318.

Morgan, J. (1984) Monoclonal antibody production. In Modern Methods in Pharmacology, S. Spector and N. Bach, eds., Vol. 2, pp. 29-67, Alan R. Liss, Inc., New York.

Moulton, D. G. (1974) Cell renewal in the olfactory epithelium of the mouse. Ann. N. Y. Acad. Sci. 237: 52-61.

Nagahara, Y. (1940) Experimentelle Studien uber die histologischen Veranderungen des Geruchsorgans nach der Olfactoriusdurchschneidung. Beitrage zur Kenntnis des feineren Baus des Geruchsorgans. Jpn. J. Med. Sci. V. Pathol. 5: 165-199.

Simmons, P. A., and T. V. Getchell (1981) Physiological activity of newly differentiated olfactory receptor neurons correlated with morphological recovery from olfactory nerve section in salamander. $\mathrm{J}$. Neurophysiol. 45: 529-549.

Tucker, D. (1971) Nonolfactory responses from the nasal cavity: Ja cobson's organ and the trigeminal system. In Handbook of Sensory Physiology. Vol. IV: Chemical Senses, Sect. 1: Olfaction, K. Beidler, ed., pp. 151-181, Springer-Verlag, Berlin. 